\title{
Biomonitoring of Ceratopogonidae (Diptera: Nematocera) using car nets
}

\author{
Andrea Tóthová, Jan Knoz, Miroslav Barták and Štěpán Kubík
}

Tóthová, A., Knoz, J., Barták, M. \& Kubík, Š. 2005: Biomonitoring of Ceratopogonidae (Diptera: Nematocera) using car nets. — Entomol. Fennica 16: 124 128.

Car nets were used to collect two samples on a forest road in Podyjí National park, the Braitava forest, Czech Republic. Sampling was done in 2002 between May 31 and June 1, and between July 30 and 31. These consisted of 10 rounds (each $10 \mathrm{~km}$ in length) from morning to dusk. Over 3,000 specimens ( 52 species) of Ceratopogonidae were captured. The results suggest that the car-net method may be efficient in ceratopogonid biomonitoring and e.g. determining their daily flight activity and swarming sites.

A. Tóthová, Masaryk University, Faculty of Science, Department of Zoology and Ecology, Kotlářská 2, 61137 Brno, Czech Republic; E-mail: tothova@sci. muni.cz

J. Knoz, Masaryk University, Faculty of Science, Department of Comparative Physiology of Animals and General Zoology, Kotlářská 2, 61137 Brno, Czech Republic

M. Barták \& Š. Kubik, Czech University of Agriculture, Faculty of Agronomy, Department of Zoology and Fishery, 16521 Praha 6-Suchdol, Czech Republic; E-mail:bartak@af.czu.cz,kubik@af.czu.cz

Received 24 May 2004, accepted 19 October 2004

\section{Introduction}

The car-net method, viz. catching flying insects using a large net attached to the roof of a car, was probably first described by Lohse (Freude et al. 1965). Basically it was an improved version of a method described by Strand (1961). Later on, Kronblad \& Lundberg (1978) discussed this method in detail, together with results obtained by this method in Sweden. They also included an illustration and a photo of the collecting device. A similar approach was used by Rutanen \& Muona (1982) who concluded that car nets were effective and fast in collecting (and detecting the presence of) many beetles, especially ptilids and aleocharines. The authors suggested its use for determining swarming sites and times e.g. for scoly- tids. The method has since then faced some further improvements. Some researchers have suggested that car nets mounted low (above the ground) and into the front of vehicles can be more efficient (Dr. L. Masner, pers. comm., Peck \& Cook 1992).

Recent results of using this method were published by Koehler (1994) and Herrmann (2001). However, mounting a net in this position may be more difficult and even prohibited by legislation of some countries.

\section{Material and methods}

During 2002, two samples were collected in Podyjí National park, on the forest road in the 


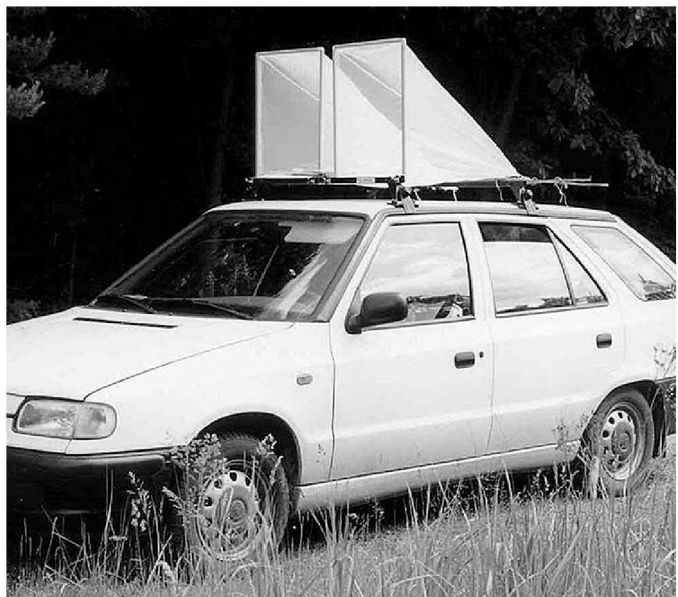

Fig. 1. Car nets mounted on the roof of a car.

Braitava forest of the Czech Republic, using car nets (Fig. 1). Both samples (May 31 - June 1 and July 30-31) consisted of ten ca. 10-km long rounds from morning to dusk, and thus totalled about $200 \mathrm{~km}$.

Two car nets of $41 \mathrm{~cm} \times 58 \mathrm{~cm}$ were mounted on the roof of a car (Fig. 1). The nets were made of monofil ${ }^{\circledR}$ attached to a metal frame. A small dose of "knock-down" pyrethroid insecticide was applied to tip of each net before each sampling round to prevent escapes of flies. After each round, nets were emptied into entomological net and the material was immediately stored in $70 \%$ ethanol.

The material was then sorted in the laboratory using dissecting microscope with $20 \times$ magnification, and specimens were subsequently identified. Only about $1 / 5$ of the total sample was selected for identification in the case of common morphospecies and progressively higher proportion in the case of rare morphospecies. Simultaneously we performed an assessment of the total number of ceratopogonids applying the 1/10 method (Barták 1997) that indicated that we captured about 3,200 specimens of biting midges.

Specimens were mounted on microscope slides in phenol alcohol or, for some problematic specimens, Canada balm, and identification was done using monographs and keys by ZilahiSebess (1940), Remm (1969), Wirth et al. (1974), Havelka (1976) and Szadziewski (1983). Species of the genus Culicoides were treated by Országh (1980).

For identification of species of the genus Atrichopogon, we used papers by Remm (1961a), Havelka (1979), Wirth (1980), Országh \& Košel (1995) and Szadziewski et al. (1995, 1996). For identification of Forcipomyia species, we used papers by Remm (1960, 1961b), Krivosheina (1968), Dow \& Wirth (1972), Wirth (1972) and Wirth \& Ratanaworabhan (1978). For species of Ceratopogon, the key provided by Borkent \& Grogan (1995) was used, whereas species of Dasyhelea, Bezzia and Palpomyia were identified using keys of Remm (1962, 1974a, 1974b, 1974c, 1976). All species of the Palaearctic region are listed in Remm (1988). Recent nomenclature was used including the changes by Borkent \& Wirth (1997) and Szadziewski \& Knoz (2002).

\section{Results}

Results of species identification are presented in Table 1. Precise counting of selected material is given under "identified specimens" but the true abundance of each species may well be $3-5$ times higher. In our samples, altogether 52 species of 10 genera were found, which represents about $26 \%$ of the total Czech ceratopogonid fauna. Eleven species are first records from the territory of the Czech Republic (Tóthová et al. 2004, in press).

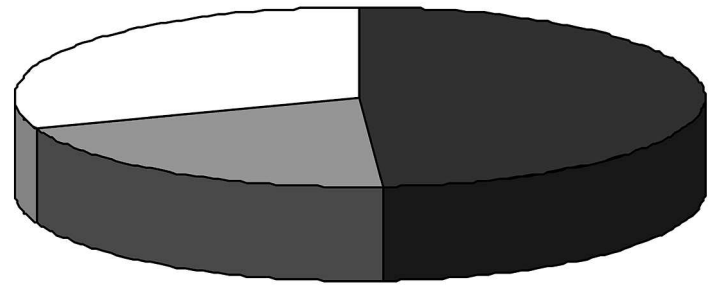

$\square$ Haematophagous - 357

$\square$ Phytosuccivorous - 150

$\square$ Ectoparasitic - 225
Fig. 2. Number of specimens of trophic groups captured using car net. 
Table 1. List of identified species collected using car net. In the present study, the estimated mean abundance of ceratopogonids was ca. 1 specimen per $30 \mathrm{~m}^{3}$ of air, for the height of ca. $1.5-2 \mathrm{~m}$ above ground level.

\begin{tabular}{|c|c|c|}
\hline Species & Males & Females \\
\hline Culicoides (Avaritia) obsoletus (Meigen, 1818) & 6 & 55 \\
\hline C. (Culicoides) punctatus (Meigen, 1804) & - & 48 \\
\hline C. (Oecacta) fascipennis (Staeger, 1839) & 2 & 47 \\
\hline C. (O.) festivipennis Kieffer, 1914 & - & 48 \\
\hline C. (O.) kibunensis Tokunaga, 1937 & - & 25 \\
\hline C. (O.) pallidicornis Kieffer, 1919 & - & 1 \\
\hline C. (O.) pictipennis (Staeger, 1839) & - & 6 \\
\hline C. (O.) reconditus Campbell \& Pelham-Clinton, 1960 & - & 1 \\
\hline Ceratopogon naccinervis Borkent, in Borkent \& Wirth 1997 & - & 3 \\
\hline Stilobezzia (Stilobezzia) flavirostris (Winnertz, 1852) & - & 2 \\
\hline Stilobezzia (Acanthohelea) ochracea (Winnertz, 1852) & - & 2 \\
\hline Schizohelea leucopeza (Meigen, 1804) & - & 17 \\
\hline Serromyia femorata (Meigen, 1804) & 2 & 2 \\
\hline S. morio (Fabricius, 1775) & 2 & - \\
\hline S. subinermis Kieffer, 1919 & - & 5 \\
\hline Bezzia (Bezzia) signata (Meigen, 1804) & 12 & 0 \\
\hline Bezzia (B.) winnerztiana Kieffer, 1919 & 14 & 0 \\
\hline Bezzia (Pygobezzia) albicornis (Meigen, 1818) & - & 1 \\
\hline Palpomyia melacheira Remm, 1976 & - & 1 \\
\hline P. nigripes (Meigen, 1830) & - & 2 \\
\hline P. serripes (Meigen, 1818) & 1 & 8 \\
\hline P. tibialis (Meigen, 1818) & - & 1 \\
\hline Dasyhelea (Dasyhelea) malleola Remm, 1962 & 4 & 4 \\
\hline D. (D.) pallidiventris (Goetghebuer, 1831) & - & 2 \\
\hline D. (D.) paludicola Kieffer, 1925 & 1 & - \\
\hline D. (D.) saxicola (Edwards, 1929) & 15 & 10 \\
\hline D. (D.) septuosa Borkent [in Borkent \& Wirth (1997)] & 2 & 27 \\
\hline D. (D.) versicolor (Winnertz, 1852) & - & 1 \\
\hline D. (Dicryptoscena) modesta (Winnertz, 1852) & - & 1 \\
\hline D. (Pseudoculicoides) flavoscutellata (Zetterstedt, 1850) & - & 13 \\
\hline D. (Prokempia) flaviventris (Goetghebuer, 1910) & - & 25 \\
\hline Atrichopogon (A.) brunnipes (Meigen, 1804) & 1 & 3 \\
\hline A. (A.) hirtidorsum Remm, 1961 & 1 & 8 \\
\hline A. (A.) minutus (Meigen, 1830) & 3 & 1 \\
\hline A. (A.) pavidus (Winnertz, 1852) & - & 1 \\
\hline A. (Meloehelea) aff. epicautae (Wirth, 1956) & - & 10 \\
\hline A. (M.) lucorum (Meigen, 1818) & 22 & 46 \\
\hline A. (M.) oedemerarum Storå, 1939 & - & 11 \\
\hline A. (M.) winnertzi Goetghebuer, 1922 & 9 & 36 \\
\hline A. (Psammopogon) flavolineatus Strobl, 1880 & - & 8 \\
\hline Forcipomyia (Euprojoannisia) palustris (Meigen, 1804) & 2 & 8 \\
\hline F. (E.) titillans (Winnertz, 1852) & - & 3 \\
\hline F. (Forcipomyia) bipunctata (Linnaeus, 1767) & 1 & - \\
\hline F. (F.) brevipennis (Macquart, 1828) & - & 2 \\
\hline F. (F.) hygrophila Kieffer, 1925 & - & 2 \\
\hline F. (F.) kaltenbachi (Winnertz, 1852) & - & 6 \\
\hline F. (F.) nigra (Winnertz, 1852) & 5 & - \\
\hline F. (F.) tenuis (Winnertz, 1852) & - & 1 \\
\hline F. (F.) tenuisquama Kieffer, 1924 & - & 1 \\
\hline F. (Lasiohelea) sibirica (Bujanova, 1962) & 23 & 86 \\
\hline F. (L.) velox (Winnertz, 1852) & 3 & 6 \\
\hline F. (Thyridomyia) monilicornis (Coquillet, 1905) & 1 & 3 \\
\hline Total & 132 & 600 \\
\hline
\end{tabular}




\section{Discussion}

Biting midges are usually collected using various kinds of light traps, $\mathrm{CO}_{2}$-baited traps, traps baited with nulliparous females, or using Malaise traps. In collecting biting midges, the car-net method appears to substantially enrich the portfolio of the traditional collecting methods. It also seems to be efficient in collecting biting midges with diurnal and crepuscular activity. Of the 19 genera of biting midges known from the Czech Republic, 10 were captured in our study, suggesting that the car-net method is an effective way to sample entire ceratopogonid faunas in diverse habitats. The qualitative and quantitative richness of our material, collected in Podyjí National Park, reflects the usefulness of this collecting method, and the overall midge abundance in this area. About $1 / 3$ of our material were species of the haematophagous genus Culicoides (especially females). This well-studied genus, of veterinary and medical importance, is usually captured using light traps, but its high proportion in our samples shows the utilisation and efficiency of our method. We also collected haematophagous species of the subgenus Lasiohelea of Forcipomyia that feed on the blood of amphibians (L. velox) and mammals, including man ( $L$. sibirica). Females of the genera Atrichopogon, Forcipomyia, Palpomyia, Stilobezzia and Serromyia feed on the haemolymph of other insect groups (Diptera, Coleoptera, Odonata and Lepidoptera). All other genera are phytosuccivorous and pollinovorous.

The car-net method appears to be able to capture not only some of the trophic groups of selected families, but also the entire spectrum of species and their feeding specifications. The diversity of trophic groups in our two samples is another advantage of this method (Fig. 2).

Some species could not be identified because of the poor knowledge of several species groups in the genus Forcipomyia. For example, Atrichopogon (Meloehelea) epicautae was identified sensu Wirth (1980), but this may actually be a form of A. lucorum. The subgenus Meloehelea in the Czech Republic is currently being analysed applying $16 \mathrm{~S}$ rDNA sequences. Moreover, because of the quantitative richness of the examined samples, some specimens may have been overlooked, as some species known from South Mo- ravia were missing in our samples (Knoz 1998). Possible examples are at least Probezzia and Sphaeromias species.

In general, biting midges have two abundance peaks: late spring and the onset of autumn. The capture of $26 \%$ of known Czech species outside their peak abundance period is another indication of the high efficiency of the collecting method used. It also seems to be succesful for quick monitoring of local populations of other dipteran groups.

Acknowledgements. We are indebted to the Masaryk University of Brno for financial support (grant no. MSM 143100010 and 0021622416 ). This paper was partly supported by IRP MSM 6046070901.

\section{References}

Barták, M. 1997: The biomonitoring of Diptera by means of yellow pan water traps. - In: Vaňhara, J. \& Rozkošný, R. (eds.), Folia Fac. Sci. Nat. Univ. Masaryk. Brun., Biologia 95. Dipterologica Bohemoslovaca 8: 9-16.

Borkent, A. \& Grogan, W. L. 1995: A revision of the genus Ceratopogon Meigen with a discussion of phylogenetic relationships, zoogeography and bionomic divergence (Diptera, Ceratopogonidae). - Mem. Ent. Soc. Wash. 15: 1-198.

Borkent, A. \& Wirth, W. W. 1997: World species of biting midges (Diptera, Ceratopogonidae). - Bulletin Amer. Mus. of Nat. Hist. 233: 1-257.

Dow, M. I \& Wirth, W. W. 1972: Studies on the genus Forcipomyia. II. The Nearctic species of the subgenera Thyridomyia and Synthyridomyia (Diptera, Ceratopogonidae). - Ann. Ent. Soc. Amer. 65: 177-201.

Freude, H., Harde, K. \& Lohse, G. 1965: Die Käfer Mitteleuropas, Bd. 1: Einführung in die Käferkunde. - Elsevier. 214 pp.

Havelka, P. 1976: Limnologische und Systematische Studien an Ceratopogoniden. - Beiträge zur Entomologie 26: 211-305.

Havelka, P. 1979: Atrichopogon lucorum (Meigen, 1818) [Diptera, Ceratopogonidae] - Ein neuer temporärer, canthariphiler Ektoparasit am Ölkäfer Meloe violaceus Mrsh., 1802 [Coleoptera, Meloinae]. Zeitschrift der Arbeitsgemeinschaft Österreichischen Entomologen 3-4: 117-119.

Herrmann, A. 2001: Autokescher und Beifahrerkescher. - Mitt. Int. Ent. Vereins 26 (3-4): 155-158.

Knoz, J. 1998: Ceratopogonidae. - In: Rozkošný R. \& Vaňhara J. (eds.), Diptera of the Pálava Biosphere Reserve of UNESCO I. Folia Fac. Sci. Nat. Univ. Masaryk. Brun., Biologia 99: 113-121.

Koehler, F. 1994: Die Bedeutung der Autokescher- 
Methode für faunistisch-ökologische Käferbestandserfassungen. - Jahresberichte Nat.-wiss. Ver. 47:5662.

Krivosheina, N. P. 1968: [A contribution to the biology and morphology of little studied biting midges of the genus Forcipomyia Meigen (Diptera, Ceratopogonidae)]. - Zoologicheskij Zhurnal 47: 578-590. [In Russian.]

Kronblad, W. \& Lundberg, S. 1978: Bilhavning - en interessant fangstmetod för skalbaggar och andra insekter. - Ent. Tidskr. 99: 115-118.

Országh, I. 1980: (Ceratopogonidae.) — In: Chvála, M. (ed.), Krevsající mouchy a střečci - Diptera: 20-144. Fauna ČSSR 22, Academia, Praha. [In Czech.]

Országh, I. \& Košel, V. 1995: Redescription of Atrichopogon trifasciatus (Diptera, Ceratopogonidae) collected in three caves of Slovakia. - Acta Zool. Univ. Comenianae 39: 39 44.

Peck, S. B. \& Cook, J. 1992: Use of "car-nets" to sample flying micro-Coleoptera. — Can. Entomol. 124: 745749.

Remm, H. 1960: (Three new species of the genus Forcipomyia Meigen in Estonia.) — Eesti NSV Taeduste Akadeemia Juures Asuva Loodusuurijate Seltsi Aastaraamat 53: 188-194. [In Russian.]

Remm, H. 1961a: [Estonian species of the genus Atrichopogon Kieffer (Diptera, Heleidae). II. Description of three new species and key to the Estonian species of the subgenus Atrichopogon s. str.] Entomologicheskoe Obozrenie 40: 920-928. [In Russian.]

Remm, H. 1961b: [A survey of species of the genus Forcipomyia Meigen (Diptera, Heleidae) from Estonia.] - Eesti NSV Taeduste Akadeemia Juures Asuva Loodusuurijate Seltsi Aastaraamat 54: 165-195. [In Russian.]

Remm, H. 1962: [The genus Dasyhelea Kieffer (Diptera, Heleidae) in Estonia] — Zoologia - Alaseid Töid 2: 108-133. [In Russian.]

Remm, H. 1969: [Ceratopogonidae (Heleidae)]. — In: Bej-Bienko, G. Ja. (ed.), Opredelitel nasekomych jevropejskoj časti SSSR: 201-218. 5/1 Dvukrylye, Blochi. Izd. Nauka, Leningrad. [In Russian.]

Remm, H. 1974a: [A review of species of the genus Bezzia Kieffer (Diptera, Ceratopogonidae) from the fauna of the USSR. I.] - Entomologicheskoe Obozrenie 53: 429 442. [In Russian.]

Remm, H. 1974b: [A systematic review of species of the genus Ceratopogon Meigen (Diptera) from USSR.] - Zoologia - Alaseid Töid 8: 23-58. [In Russian.]

Remm, H. 1974c: [A review of species of the genus Bezzia Kieffer (Diptera, Ceratopogonidae) from the fauna of the USSR. II. Subgenus Bezzia s.str.] — Entomologicheskoe Obozrenie 53: 888-902. [In Russian.]

Remm, H. 1976: A synopsis of the Palpomyia of the USSR (Diptera, Ceratopogonidae). - Eesti NSV Taeduste Akadeemia Juures Asuva Loodusuurijate Seltsi Aastaraamat 64: 172-197.

Remm, H. 1988: Ceratopogonidae. — In: Soós, A. \& Papp, L. (eds.), Catalogue of Palaearctic Diptera Vol. 3, Akadémia, Budapest. 448 pp.

Rutanen, I. \& Muona, J. 1982: Coleoptera collected with a car-net in Finland. - Not. Ent. 62: 69-72.

Strand, A. 1961: Fangst av flygende biller (Coleoptera). Norsk. Entomol. Tidssk. 11: 244-247.

Szadziewski, R. 1983: Ceratopogonidae (Diptera) from Algeria. II. New species, new records and new synonymy in the genus Forcipomyia Meig. - Pol. Pis. Ent. 53: 363-384.

Szadziewski, R., Gilka, W. \& Anthon, H. 1995: Immaturate stages of two European species of the subgenus Meloehelea (Diptera, Ceratopogonidae), with keys to the European subgenera of Atrichopogon. - Ent. Scand. 26: 181-190.

Szadziewski, R., Kaczorowska, E. \& Krzywiński, J. 1996: Redescription of some European species of Atrichopogon (Diptera, Ceratopogonidae). — Pol. Pis. Ent. 65: 297-318.

Szadziewski, R. \& Knoz, J. 2002: New synonyms of European biting midges (Diptera, Ceratopogonidae). Ann. Zool. 52: 249-251.

Tóthová, A., Barták, M. \& Knoz, J. 2004: Ceratopogonidae of Southern Moravia (NP Podyjí). - Acta Facultatis Ecologiae, Suppl. Dipterologica Bohemoslovaca 12: 143-148.

Wirth, W. W. 1972: The neotropical Forcipomyia (Microhelea) species related to the caterpillar parasite $F$. fuliginosa (Diptera, Ceratopogonidae). - Ann. Ent. Soc. Amer. 65: 564-577.

Wirth, W. W. 1980: A new species and correction in the Atrichopogon midges of the subgenus Meloehelea attacking blister beetles (Diptera, Ceratopogonidae). Proc. Ent. Soc. Wash. 82: 124-139.

Wirth, W. W., Ratanaworabhan, N. C. \& Blanton, F. S. 1974: Synopsis of the genera of Ceratopogonidae (Diptera). - Annales de Parasitologie 49: 595-613.

Wirth, W. W. \& Ratanaworabhan, N. C. 1978: Studies on the genus Forcipomyia. V. Key to subgenera and description of a new subgenus related to Euprojoannisia Brčthes (Diptera, Ceratopogonidae). — Proc. Ent. Soc. Wash. 80: 493-507.

Zilahi-Sebess, G. 1940: (Heleidae from Hungary.) Folia Ent. Hung. 5: 10-133. [In Hungarian.] 